\title{
FACTORS INFLUENCING THE PRODUCTION OF HIGH QUALITY AGGREGATES FOR THE CIVIL CONSTRUCTION INDUSTRY AND THE ESSENTIAL NEED FOR CRUSHER AUTOMATION.
}

\author{
Eric Trueman \\ General Manager \\ Nordberg Asia Pacific Regional Sales Support Group \\ Perth Australia \\ eric.trueman@nordberg.com
}

\begin{abstract}
Increasingly higher specifications for concrete and roadway structures required by the Construction Industry worldwide, demand the high volume production of aggregates with the highest possible cubicity.

This paper looks at the use of advanced crushing technology, circuit design and importantly the need for crusher automation to achieve consistent quality at optimum cost. Reference is also made to the process variables which also influence the production of cubical materials and which are often disregarded.
\end{abstract}

\section{INTRODUCTION}

The global trend towards increasingly higher and stringent specifications for concrete and roadway construction demands the production of high quality aggregate materials with good shape characteristics usually expressed in terms of cubicity or flakiness index.

This paper looks briefly at some of the overall process variables which influence the production of these materials, optimal circuit design and Process Automation. This is required for the control of the crushers, feeding devices, screens and the other items of equipment that comprise a crushing circuit to ensure optimum production cost and continuous product quality as well as for the supervision and condition monitoring the whole plant.

For thousands of years, mankind has been utilising the "comminution process" to convert massive rock or gravel from the earth's surface to a state that can be used to develop infrastructure and improve quality of life by the construction of buildings and roadways. Simply stated, comminution is" the breaking of big rocks into little rocks" and at first glance appears to be a simple basic process.

In some parts of the world, this basic process has remained unchanged and is still practised using manual labour, simple tools and processes. It is possible to produce reasonable quality aggregates by hand but in quantities so small that they are insignificant to meet the needs of global requirements.
Mechanical crushing devices have been developed since the introduction of stamp mills in 1830 to satisfy

the growing requirements for crushed aggregates needed for global industrial and urban development. The highly developed and competitive market environment has focussed both equipment suppliers and plant operators to achieve highest productivity at the lowest operating costs with greater emphasis on product quality. Today, this is accomplished by integrating the most advanced crusher designs and process automation.

\section{CURRENT TRENDS}

Investigations by civil engineering and construction industry research organisations have shown that significant overall cost savings are achievable by using aggregates with high cubicity (low flakiness) values in the construction of roadways and concrete structures as the result of the following-:

\footnotetext{
-Improved mechanical properties

-Improved wear resistance

-Reduction in bitumen content in asphalt materials

-Concrete with better flowability and strength characteristics

.... to form complex profiles

-And many more benefits
} 
The economic life of civil structures can be increased and the construction and maintenance costs can be significantly reduced by the judicious use of materials

that are inherently cubical in shape. The use of materials with higher flakiness values which have a

greater disposition to breakage under the imposition of loads will require more frequent, costly and disruptive repair work to be undertaken.

Cubicity standards exist in most developed countries of the world. The standard form of shape determination utilises either special sieve or gauges on a predetermined number of particles in any one size fraction. Most specifications follow the same principle of measurement however the definition of acceptance values differs from standard to standard. Applicable internationally accepted standards include DIN, British Standards, ASTM and Japanese.

The Nordberg Group makes significant investments in engineering research to maintain its leadership in advanced crusher designs, crushing member metallurgy and profile development together with optimal circuit design to achieve high end product quality. Many other extraneous factors do however influence product quality. These include the mineralogy and types of rock processed, deleterious material components, moisture content, mode of feed, feed regulation and many associated issues. These variables demand the integration of fully automated total plant monitoring and control systems to ensure that maximum overall process benefits are achieved.

Each of the topics mentioned above justifies a separate presentation to convey the complexities involved in achieving the end results desired. Time constraints restrict this, nevertheless a brief overview is given to some of the most important elements of ADVANCED CRUSHING TECHNOLOGY and CRUSHER / CIRCUIT AUTOMATION with the objective of achieving lowest operating costs and highest productivity of quality materials.

It will be shown that the basic process of breaking big rocks into little rocks is easy. The cost effective production of high quality materials is more complex and requires specialist knowledge.

\section{FACTORS INFLUENCING PRODUCT QUALITY >> CUBICITY}

\subsection{Mineral and Rock Types}

Crushing hard rock does not necessarily produce good shape. In fact the opposite can be true. An analysis of the rock to determine its microstructure and chemical composition can indicate whether the rock will have a natural propensity to produce cubical or flaky products when crushed. In reality the hardness of minerals used

for construction purposes do not vary drastically but their properties can vary considerably. Rock types consisting of the same minerals can exhibit entirely different strength characteristics. Granite for example is regarded as an average strength material generally well suited for aggregate production, but certain granites are extremely strong whereas others are weak and this can be attributed to their microstructure. Unfortunately not all Aggregate plant operators appreciate the significance of the rock type on the shape specifications that they are expected to meet nor the design complexity and related cost of the crushing circuit required.

As a general rule of thumb, the softer the rock the better the cubicity of the crushed aggregate. Fine crystal structures usually indicate hard rock with the clear trend towards the production of aggregates with higher flakiness values. Every application must however be considered individually, since it is the writer's opinion that there is no single process solution for all feed material types and conditions or product requirements.

\subsection{Feed Control}

One of the most important factors for good product shape is the requirement of a "choke feed" condition. This requires material to fill the crushing cavity to the point where maximum power can be drawn but without flooding the crusher. In Advanced Crushing Technology, multi layered crushing takes place with the increased predominance of interparticle crushing contributing to the production of cubical material. If the cavity is underfed, coarser less cubical products can be expected, supporting the need for automation. Level sensors of various types ranging from simple contact probes to ultrasonic and lasers linked to some method of feed control are used for this purpose.

The moisture content of the feed material can significantly influence the capacity of a crusher and product quality of the crushed material. At tight closed side settings, required for the production of fine material, a total moisture content as low as $2-3 \%$ can reduce crusher throughput by $<40 \%$ due to the material exhibiting sluggish handling characteristics. An increase in retention time in the crushing cavity can make a marginal improvement in cubicity but this is traded against lower capacity. Under these operating conditions, it is also frequently found that excessive power draw and unacceptable adjustment ring or head movement occurs as the result of material packing in the crushing chamber. Corrective action such as stopping the feeder or increasing the crusher setting needs to be implemented to ensure 
that the mechanical integrity of the crusher is not compromised, again supporting the need for automation.

If the feed material is either devoid or contains an excess of a particular size fraction it is said to be "GAP Graded". This can cause an even wear of the crushing members requiring the bowl liner and mantle to be changed prematurely whilst at the same time reducing the interparticle crushing to occur resulting in a less cubicle finished product. Similarly a segregated or non-homogeneous feed introduced into the crushing cavity will cause uneven wear on the crushing members and also results in the product shape being compromised. In this case more frequent incremental adjustments to the crusher setting are required.

Product shape is also compromised when operating at high reduction ratios. This is where small material is required to be produced from large feed in a single crushing stage.

It is important that a thorough appreciation of these and other important factors associated with the feeding system are identified and controlled if high product quality is required. Hence the need and benefits for crusher automation is clearly identified.

\subsection{Crusher Design}

We shall deal only with Cone crushers in this paper due to limitations on time, however many of the general principles covered herein are equally applicable to impact crushers which are mostly used for crushing soft, friable and non abrasive materials.

Cone crushers are the most widely used machine throughout the world for the cost effective size reduction of hard abrasive rocks such as granite, basalt etc. which are the preferred material types for high strength and abrasion resistant duties in concrete and road construction. For optimisation of performance, maximum power draw and a constant closed side setting control with regulated feed conditions are required.

All cone crushers are subject to production limitations due to the following parameters.

\section{Volume Limit}

Power Limit

Force Limit

\section{Volume Limit}

The volume limit is reached when the rate of feed material that can fall through the crushing cavity in a series of steps where size reduction progressively takes place is exceeded by the rate at which the crusher is being fed. The maximum volumetric flow is influenced by the size, setting, speed, throw and shape of the crushing cavity as well as the material characteristics and feed size distribution mentioned above.

Power Limit.

The crusher frame and drive components are designed to operate with a defined level of installed power. The selection of the motor size is based on the crusher operating within anticipated capacity levels. Once the maximum power level of the motor is reached further increases in capacity or size reduction will result in overload and the shortening of component life. The crusher has reached its power limit.

Factors, which influence the power draw of a cone crusher and cavity profile, include inter alia the characteristics of the rock being crushed, feed rate, closed side setting, size reduction ratio etc.

\section{Force Limit}

Cone crushers are designed to operate within defined structural and mechanical limits. Forces generated within the crushing cavity, which are greater than the design limit must be relieved by some means to avoid damage. This can be either a preloaded mechanical or hydraulic mechanism that serves as the safety device.

The crushing force may be reached by the presence of uncrushable material entering the crushing cavity or the result of the complex forces which result due to the material type, feed rate, setting and crusher mode etc.

Extensive research and development together with field testing over many years in what is known as the Crusher Variables Programme has been undertaken by Nordberg design engineers. The relationship between the size and shape of the crushing chamber together with the speed of operation and volumetric capability of the crushing chamber have been established. The effects of machine geometry, dynamics of operation and engineering design were studied and the relationship between volume, crushing force capability and power matched to provide the most advanced crushing technology available to the industry.

Figure 1 illustrates that the overall productivity of a crusher is dictated by the parameter which is reached first in operation. Where the force, power and volume limits are evenly matched, overall crusher productivity will be maximised. This oversimplification of the continuous and extensive research and development in matching these three limiting factors forms the basis of Nordberg MP, HP and G Cone Advanced Crushing Technology. This is a major contributory factor in producing the quality 

industry. aggregate products required by the construction

crushing including open or closed circuit operation have to be considered depending on the product and process specifications as well as overall capital cost. There is no one circuit design solution which meets all market requirements. Each circuit must be evaluated and designed to meet specific process demands. There is however no reason to produce material having a quality standard far in excess of that required since this will necessitate increased capital investment and result in uncompetitive production costs.

A typical simple circuit optimising quantity and quality aggregate production are shown in figure 2 .

In practice bins and feeders will precede the crushers

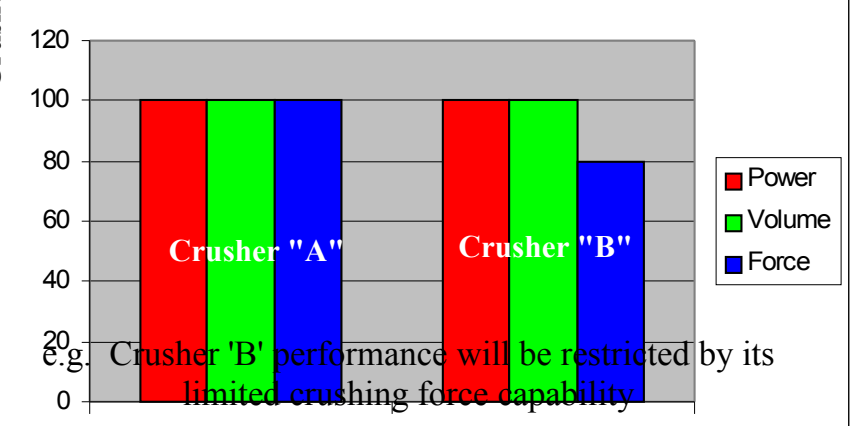

\begin{tabular}{|l|ll|l|}
\hline$\square$ Power & 100 & Figure 1 & 100 \\
\hline$\square$ Volume & 100 & & 100 \\
\hline
\end{tabular}

Forde is not alwaryo possible to deternime which of the above limits will be reached first particularly with variable feed conditions. For optimum crusher performance, maximising power draw is usually the target however each of the limits must be individually monitored and corrective action taken to ensure that the crushers design parameters are not exceeded thereby compromising the mechanical integrity of the machine or its productivity.

Nordberg's Advanced Technology Crushers all employ the extensive use of hydraulically activated systems which enable the crusher to be easily and simply integrated into stand alone or fully automated circuit. Tramp release mechanisms which allows the safe passage of uncrushable material through the crusher and hydraulic setting and locking systems enable online automatic adjustments to be made. By the continuous monitoring of crusher cavity level, power draw, crusher force level and the lubrication and hydraulic system conditions, maximum crusher performance will be achieved.

Crusher"A' Crusher automation is easily possible.

\subsection{Circuit Design}

Crushing circuits can be designed to maximise either product quantity or product quality or some intermediate cost optimised balance between the two requirements. Circuit design and product quality are greatly influenced by all the factors mentioned previously. Two, three, four or more stages of

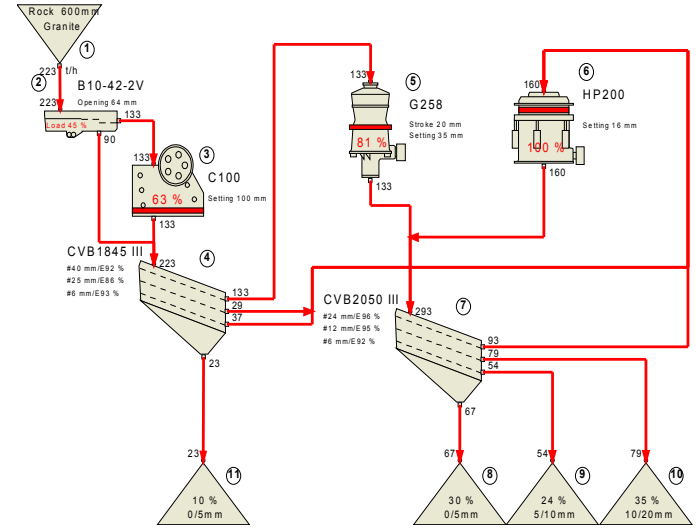

Figure 2

\section{CRUSHER \& CRUSHING PLANT AUTOMATION}

\subsection{What is Automation}

For the purposes of this paper, automation is defined as the continuous control of a process by electrical or mechanical means with minimal human effort and decisions.

\subsection{Crusher Automation}

In the 1980's, test work undertaken by Nordberg engineers demonstrated that crusher throughput increases exceeding $30 \%$ could be obtained by introducing basic crusher automation rather than by using manual control which is still common practice in many operations world-wide. This significant improvement in productivity launched an ongoing automation development programme to ensure optimum crusher productivity in terms of throughput and shape whilst at the same time reducing operational costs.

For the benefits of Advanced Crushing Technology to be maximised, the need for crusher automation has been clearly identified in terms of feed rate control, 
setting control and power control. All of these parameters need to be monitored simultaneously.

Current designs of crusher controller such as the Nordberg A2020 are suitable for head or shaft supported design crushers and can be operated in manual mode for setting up or other special purposes or in fully automatic mode. In manual and automatic modes, the controller ensures that the safety limits for setting, power or vibration are not overridden or that any of the controlled safety devices have tripped. In automatic mode, the controller also maintains the setting or power draw (depending on the predominating control parameter) in accordance with pre set values that can be edited as necessary.

In the setting control mode, the objective is to maintain the setting consistently at a pre set value to maintain a consistent product grading and a stable recirculation load. Automatic calibration and wear compensation functions enable this criteria to be met using previously established calibration results and full load power.

In the power control mode, the objective is to achieve a constant power draw. Where the power draw over a predetermined period differs from the set power value, the crusher setting will automatically increase or decrease accordingly.

The feed rate control mode is always operational and will ensure that the crusher is continuously choke fed. As the material level changes are detected by the level monitor, the feed rate will be adjusted accordingly.

This oversimplification of the crusher controllers' function is intended to outline the importance of good process control to achieve production capacity and quality.

\subsection{Crushing Circuit Automation}

The overall crushing circuit, in theory, simply represents a series of performance matched pieces of unit equipment integrated with material conveying and storage units. Crushers, screens and conveyors are highly predictable items of machinery given stable operating conditions. For plant operational efficiency, consistent material, regulated feed and feeding conditions are also required. As stated previously, variable feeding conditions influenced inter alia by weather conditions, mining area and human inefficiencies etc. are commonly found and plant automation is clearly needed if process optimisation measured in terms of product quality and productivity and lowest cost are to be achieved. The following represents an overview at current practices and future intentions with respect to the necessity for full crushing circuit automation.
The Advantages of Automation Inter alia

Machines produce continuously at their design output and quality

Machines are protected from overload and

subsequent damage.

Data is generated for production and maintenance planning.

Highest overall crushing circuit productivity

Lowest possible operating costs

Reduction in Labour

Remote and automatic setting adjustment

Condition monitoring

Easy and user friendly maintenance supervision and trouble shooting

...........and many others

Time does not permit a detailed discussion of a complete crushing circuit to be made. Nevertheless, complete plant automation is now routinely considered as an essential part of modern plant design.

The primary jaw crusher setting can be adjusted by remote control. This is made possible by using a Nordberg C Jaw with its hydraulically activated setting mechanism. Feed control to the jaw crusher is fully automated and monitored by the stone level in the crushing chamber, the power drawn by the crusher and the load in the feed hopper.

Secondary and Tertiary cone crushers can operate and be automatically adjusted to compensate for wear or to accommodate changes in the pre set level, power or force conditions. The controlled feed offtake from either the surge pile or feed bins through the precise monitoring of throughput, power draw and stone level in the crushing cavity enables the optimum performance.

\subsection{The Automation evolution process}

By today's standards, very basic systems would comprise electromechanical Man Machine Interface (MMI) using push buttons, lamps and switches. Intelligence is localised and essentially very little field feedback information is possible. Trouble shooting is difficult and time consuming, and any modifications to the system are difficult to implement. Nevertheless, many operations particularly in the less sophisticated markets still use this system.

The introduction of PLC's allowed engineers the capability to more easily modify the systems, however trouble shooting remained as elusive as ever with no feedback information flow. MMI was still realised through push buttons, lamps and switches and intelligence was still localised. Trouble shooting still proved to be extremely difficult 
The potential of PLC's was eventually recognised with MMI undertaken by video monitor displays, with centralised intelligence and feedback through the terminal. These systems were relatively more complex and allowed easier up grading and trouble shooting to be piloted by information feedback.

PLC's have now become the preferred option allowing MMI through PC with supervisory software packages. Intelligence remains centralised but with complete information feedback. Whilst the systems are much more flexible they still remain complex with trouble shooting a job for skilled experienced professionals

Whilst PLC's still remain the primary plant interface, PC software packages have become more popular. MMI is achieved on PC Windows and the operators now have vision of Trend Graphs, Alarm \& Event logs and animated mimic screens. Production logs can be viewed and printed as required. Intelligence remains centralised with information feedback and interactive with the potential to link with other systems. These systems provide flexibility but still remain complex and require specialist for trouble shooting.

This phase is considered to be generally the present top level of automation and automatable modules that are in use today.

The next future development phase is represented using PC's exclusively with MMI being part of the office tools. Field bus with local intelligence and distributed information will be complete and interactive. These flexible systems enable simple trouble shooting to be easily achieved. The use of modems and satellite communications will allow production data to be integrated into accounting spreadsheets remotely as production takes place.

The use of closed circuit television and Supervisory Control and Data Acquisition Systems (SCADA) are both very common and result in one or two man controlling operations producing $>1000$ t.p.h.

The highly successful KWP plant in Hong Kong designed, installed and commissioned by Nordberg during 1999 is typical of the future needs of aggregate industry being available today.

\section{WHERE TO FROM HERE?}

Crushing Technology will continue the advancement of crushers capable of producing high quality materials with increased productivity at reduced operating cost levels.

The materials to be processed will increasingly include the recycling of materials where finished quality of end product allows their inclusion, however the use of raw or blended recycled materials will remain secondary to the processing of freshly quarried material for the foreseeable future.

The natural variability of quarried material will demand the increasing use of both crusher and crushing circuit automation.

Crushing plant Marketing and Accounting will be integrated with the production plant monitoring and control functions. The automatic monitoring of finished products on stockpiles and in storage bins with material sales via the weigh-bridge will provide inventory levels and value information allowing the plant manager to implement appropriate financial control measures.

Crushing and screening plant performance requirements and their operating conditions are becoming more focussed on -:

\author{
Higher Productivity \\ Lower Cost Per Tonne \\ Increased Profitability \\ Security \\ Cleanliness \\ Safety
}

The operational costs, the product quality and consistent performance demanded by the visionary aggregate producers are the key factors which require ongoing research on the design of complete plants.

"Smart" crushers and screens will become common. They already exist. Performance and condition monitoring will be undertaken routinely and information automatically relayed back to the Quarry owner or more likely to the equipment manufacturer to initiate routine maintenance or problem solving at a distance using integrated modems. With the ability of making automatic adjustments to all the crushers in a circuit, re routing material in a crushing circuit etc. the production of special materials, high quality blending, batch production, automatic sampling with closed loop feed back into the supervisory control system etc. in accordance with electronically communicated instructions will become routine. The need or interference of operations personnel will not be required.
Many factors influence the production of cubical materials demanded to meet the increasing specifications. Advanced Crushing Technology 
capable of providing high quality products already exists and is developing further. Crusher and Crushing Plant automation is becoming more common and will be able to adjust, monitor, control and initiate human interference where and when required to accommodate the sometimes unpredictable and varying nature of the materials being crushed.

It will be the vision and initiative of crusher design and automation engineers together with Information Technology personnel who will dictate the speed that which this occurs.

\section{Acknowledgements}

Here I thank my colleagues for their contribution in the preparation of this paper.

$\begin{array}{lll}\text { Michael Caine } & - & \text { Nordberg South } \\ \text { Africa } & & \\ \text { Serge De Baker } & - & \text { Nordberg Macon } \\ & & \\ \text { Luis Santos } & - & \text { Nordberg Macon } \\ \text { Tapio Potila } & - & \text { Nordberg Tampere }\end{array}$

\section{$\underline{\text { Reference }}$}

Pekka Supila

- Senior Researcher

Geological Survey of

Finland 